\title{
Projetos de Reintegração Social do Presidiário: Uma Leitura Comportamental
}

\author{
Thais Albernaz Guimarães ${ }^{1}$ \\ Programa de Estudos Pós-Graduados em Psicologia Experimental: Análise \\ do Comportamento da Pontifícia Universidade Católica de São Paulo, São Paulo, Brasil \\ Sergio Vasconcelos de Luna \\ Departamento de Métodos e Técnicas em Psicologia da Pontifícia Universidade Católica \\ de São Paulo, São Paulo, Brasil
}

\begin{abstract}
Resumo
O presente artigo relata resultados de pesquisa que analisou, tendo como referência literatura analíticocomportamental, propostas de reintegração social para presidiários. Buscou-se identificar elementos de programação que deveriam estar presentes na formulação de um projeto de reintegração social, de modo a apresentar maior probabilidade de preparar o presidiário para enfrentar as condições ambientais uma vez fora do presídio. Como material de análise, foram considerados relatos apresentados no Manual de Projetos de Reintegração Social da Secretaria de Administração Penitenciária. No confronto entre a proposta comportamental e projetos analisados, cinco categorias foram criadas de modo a sugerir aos proponentes de um projeto de reintegração condições para torná-lo mais efetivo. A análise foi relevante para identificar lacunas e imprecisões contidas nos projetos apresentados, tornando possível apontar prováveis dificuldades na sua implementação.
\end{abstract}

Palavras-chave: análise do comportamento, reintegração social, sistema penitenciário.

\section{Penitentiary Social Reintegration Programs: A Behavioral Analysis Approach}

\begin{abstract}
The present article reports results obtained from research that analyzed Penitentiary Social Reintegration Programs based on Behavioral Analysis Approach literature. The research sought to identify programming elements which should be present in creating a Social Reintegration Project in order to increase the probability of actual preparation of the inmate to face the challenges placed by the environment once out of imprisonment. Reports of existing projects provided in the Social Reintegration Project Manual of the Penitentiary Administration Department were confronted with a Behavioral Analysis proposal for reintegration on five categories created as conditional aspects for an effective reintegration project. The analysis was relevant as it identified the missing and uncertain aspects of the projects presented, and allowed for an evaluation of probable implementation issues.
\end{abstract}

Keywords: behavior analysis, social rehabilitation, penitentiary system.

Endereço para correspondência: Pontifícia Universidade Católica de São Paulo, Rua Ministro Godoi, 969, $4^{\circ}$ andar, Perdizes, São Paulo, SP, Brasil 05015-901. E-mail: thaisalbernazguimaraes@gmail.com e svluna@ pucsp.br. 


\section{Proyectos de Reinserción Social del Preso: Una Lectura Conductual}

\section{Resumen}

Este artículo presenta los resultados de una investigación que analizó, basado en la literatura conductual, las propuestas para la reinserción social de los reclusos. La investigación buscaba identificar los elementos de programación que deben estar presentes en la creación de un Proyecto de Reinserción Social con el fin de aumentar la probabilidad de preparación real del recluso para hacer frente a los desafíos colocados por el medio ambiente una vez fuera de la cárcel. Los informes de los proyectos existentes que figuran en el Manual de Reinserción Social del Proyecto del Departamento de Administración Penitenciaria se enfrentaron a una propuesta de Análisis de Conducta para la reintegración en cinco categorías creadas como aspectos condicionales para un proyecto de reintegración efectiva. El análisis es pertinente, ya que identifican los aspectos faltantes e inciertos de los proyectos presentados, y permitió una evaluación de los posibles problemas de aplicación.

Palabras clave: analisis de la Conducta, reinserción social, sistema penitenciario.

Entre 2001 e 2010, o número de presos já condenados no Sistema Penitenciário Brasileiro aumentou de 141.297 para 514.582 (Ministério da Justiça, 2012). Ou seja, em 10 anos, o número de homens e mulheres encarcerados no país quase quadruplicou. Em março de 2011, uma pesquisa do Conselho Nacional de Justiça revelou que $70 \%$ dos presos que deixavam o sistema penitenciário voltavam ao crime $^{2}$ representando uma das maiores taxas de reincidência do mundo.

No Brasil, ações voltadas para a reintegração social do preso e prevenção da sua reincidência no crime estão, por lei, a cargo do Estado ${ }^{3}$ (Ministério da Justiça, 1984). O desafio de se re-

http://www.istoe.com.br/reportagens/157533 $\mathrm{NO}+\mathrm{BRASIL}+\mathrm{SETE}+\mathrm{EM}+\mathrm{CADA}+\mathrm{DEZ}+\mathrm{EX}+\overline{\mathrm{P}}$ RESIDIARIOS+VOLTAM+AO+CRIME+DIZ+ PRESIDENTE + DO + STF? pathImagens $=\&$ path $=$ \&actualArea $=$ internalPage

3 A Lei de Execuções Penais (LEP; Ministério da Justiça) de 1984 já institui no Art. 1 que a orientação se baseia em dois fundamentos: o estrito cumprimento dos mandamentos existentes na sentença e a instrumentalização de condições que propiciem a reintegração social do condenado. No Art. 10 da LEP é explicitado que "A assistência ao preso e ao internado é dever do Estado, objetivando prevenir o crime e orientar o retorno à convivência em sociedade". alizar programas efetivos de reintegração social para presidiários começa em sua formulação.

O estudo de Guimarães (2008) analisou 67 projetos apresentados no Manual de Projetos de Reintegração Social ${ }^{4}$ [um documento elaborado pela Secretaria da Administração Penitenciária (SAP), órgão do Governo do Estado de São Paulo, concluído em fevereiro de 2005], contendo programas e projetos de reintegração formulados por técnicos do sistema. Tal análise abarcou tanto os aspectos de planejamento de programas de reintegração de presidiários, quanto aqueles relativos à sua implantação, deduzidos a partir das propostas contidas em projetos para o desenvolvimento de programas. Essa análise se baseou, por um lado, nas instruções elaboradas para os autores de projetos de reintegração social (MPRS) e, por outro, em propostas da análise do comportamento para o planejamento de contingências comportamentais.

$\mathrm{Na}$ apresentação do MPRS é informado ao leitor o intuito do trabalho: "a preocupação era, e ainda é, a de se perseguir, de alguma forma, a sistematização do trabalho técnico em torno dessas ações [de Reintegração Social]" (SAP, 2005, p. 22). A proposta era a de sistematizar instruções que pudessem auxiliar técnicos do sistema

4 Doravante simplesmente designado como MPRS. 
penitenciário a criar projetos com chances de sucesso. A partir disso, Guimarães (2008) procurou identificar, nos próprios projetos estudados, características que pudessem responder pelo seu eventual sucesso. Os parâmetros para essa análise foram encontrados no referencial analíticocomportamental. O resultado dessa busca foi um roteiro de perguntas explicitado na Tabela 1, que lista, na coluna da esquerda, as categorias criadas, e na coluna da direita, as questões que foram formuladas a propósito de cada categoria.

Esse instrumento foi utilizado muito mais para explicitar lacunas e suas implicações em projetos do que propriamente como instrumento de uma análise comportamental, uma vez que nos projetos descritos não se pode encontrar muitas das informações esperadas, como será exemplificado ao longo do artigo.

Antes de prosseguir, é fundamental registrar que o simples fato de os programas não terem sido elaborados segundo um referencial comportamental enviesa o confronto de forma desfavorável aos programas. No entanto, o que se procurou foi verificar que predição de sucesso seria possível fazer com base nas propostas feitas pela Análise do Comportamento.

O ponto inicial desse trabalho foi o texto de Holland (1978), que descreve os presidiários como uma das vítimas do sistema social em que vivem e afirma que a ciência do comportamento deveria estudar esta parcela da população e criar alternativas para ela. O principal argumento da tese defendida pelo autor se baseia na impossibilidade de sucesso de qualquer procedimento de trabalho com o presidiário caso não sejam levadas em conta as condições que vigoram em seu ambiente natural. ${ }^{5} \mathrm{E}$, neste sentido, segundo ele, deve-se, em primeiro lugar, identificar as variáveis determinantes do repertório de comportamentos que levaram o infrator à prisão. Então, toda e qualquer tentativa de reintegração social do presidiário precisa, em segundo lugar,

5 De fato, a tese vale para qualquer contingência de controle do comportamento. A menção específica ao presidiário prende-se aos objetivos declarados do estudo. prepará-lo para enfrentar o ambiente novo ou ao antigo no qual ele voltará a viver.

A revisão da literatura revelou que analistas do comportamento ocuparam-se da questão da reintegração social de indivíduos que cumpriam pena privativa de liberdade, e que grande número de intervenções e artigos datam das décadas de 1980/1990 (Andrews, Bonta, \& Hoge, 1990; Andrews, Bonta, Hoge, Zinger, Gendreau, \& Cullen, 1990; Cullen, Lutze, Link, \& Wolfe, 1989; Davidson \& Seidman, 1974; Ellis, 1991; Emery \& Marholin, 1977; Holland, 1978; Latessa, 2004; Popham \& Baker, 1978b; Reppucci \& Saunders, 1974; Sidman, 1989; Skinner, 1953/1981; Susman \& Nietzel, 1990). Os estudiosos conduziram análises que indicavam ora razões pelas quais programas voltados para reintegração social de presos foram mal sucedidos, ora razões pelas quais foram bem sucedidos; algumas vezes, ainda, apontavam revisões de pontos relevantes que deveriam constar em programas de reintegração social.

O presente artigo arrola e explicita algumas condições que deveriam estar presentes na formulação de um projeto de reintegração social, de modo a apresentar maior probabilidade de preparar o presidiário para enfrentar as condições ambientais uma vez fora do presídio, diminuindo, dessa forma, a taxa de reincidência. Essas condições foram aqui organizadas em cinco campos, a saber: população-alvo, objetivos dos projetos, procedimentos empregados, avaliação, condições contextuais. Os exemplos que seguem em cada uma das categorias foram retirados do Manual de Projetos de Reintegração Social.

6 Apesar de se tratar de textos que já podem ser considerados antigos, eles foram tomados como fontes pelo menos por duas razões: (a) $\mathrm{O}$ fato de terem se tornado referências para autores mais recentes que se ocuparam do assunto por eles cobertos; (b) São as principais fontes de dados em Análise do Comportamento sobre trabalhos e pesquisas sobre reeducação de presidiários. 


\section{Tabela 1}

Categorias Criadas com Base na Literatura Analítico-Comportamental e Questões Formuladas a Propósito de Cada Categoria

\begin{tabular}{|c|c|}
\hline Categorias & Aspectos a serem considerados \\
\hline População-alvo & $\begin{array}{l}\text { Quem são os indivíduos contemplados pela intervenção? Que caracterís- } \\
\text { ticas dos mesmos são levadas em consideração? (Andrews, Bonta, \& Hoge, } \\
\text { 1990; Andrews, Bonta, Hoge, Zinger, et al., 1990; Cullen et al., 1989; La- } \\
\text { tessa, 2004; Reppucci \& Saunders, 1974) }\end{array}$ \\
\hline \multirow[t]{3}{*}{ Objetivos dos projetos } & $\begin{array}{l}\text { Os objetivos são claros e relevantes? (Andrews, Bonta, \& Hoge, 1990; An- } \\
\text { drews, Bonta, Hoge, Zinger, et al., 1990; Popham \& Baker, 1978a) }\end{array}$ \\
\hline & $\begin{array}{l}\text { A intervenção é individualizada? (Davidson \& Seidman, 1974; Popham \& } \\
\text { Baker, 1978a; Susman \& Nietzel, 1990) }\end{array}$ \\
\hline & $\begin{array}{l}\text { É especificado o comportamento-alvo em termos de comportamentos } \\
\text { observáveis? (Popham \& Baker, 1978a; Susman \& Nietzel, 1990) }\end{array}$ \\
\hline \multirow[t]{5}{*}{ Procedimentos empregados } & $\begin{array}{l}\text { Em que medida o indivíduo ou o grupo é incitado a tomar um papel ativo } \\
\text { no programa? }\end{array}$ \\
\hline & $\begin{array}{l}\text { Frequência e duração do projeto, especialmente porque tais dados permi- } \\
\text { tirão avaliar oportunidades concedidas para a emissão de comportamentos } \\
\text { e sua consequenciação. É dada aos participantes oportunidade de mode- } \\
\text { lagem e modelação dos comportamentos-alvo? (Holland, 1978; Sidman, } \\
\text { 1989) }\end{array}$ \\
\hline & $\begin{array}{l}\text { Que consequências estão sendo previstas/liberadas para que comporta- } \\
\text { mentos de quais envolvidos no projeto? (Sidman, 1989) }\end{array}$ \\
\hline & $\begin{array}{l}\text { Que relação temporal existe nesta liberação de consequências? (Ellis, } \\
\text { 1991; Skinner, 1953/1981) }\end{array}$ \\
\hline & $\begin{array}{l}\text { Que relação se estabelece entre as condições empregadas no projeto e si- } \\
\text { tuações que provavelmente o indivíduo enfrentará uma vez reintegrado à } \\
\text { sociedade? (Holland, 1978; Sidman, 1989; Susman \& Nietzel, 1990) }\end{array}$ \\
\hline \multirow[t]{3}{*}{ Avaliação } & Como é planejada a avaliação do programa? (Davidson \& Seidman, 1974) \\
\hline & $\begin{array}{l}\text { Medidas observáveis são utilizadas? (Davidson \& Seidman, 1974; Popham } \\
\text { \& Baker, 1978a, 1978b) }\end{array}$ \\
\hline & $\begin{array}{l}\text { É planejada a coleta de dados de follow-up? (Davidson \& Seidman, 1974; } \\
\text { Emery \& Marholin, 1977; Susman \& Nietzel, 1990) }\end{array}$ \\
\hline \multirow[t]{3}{*}{ Condições contextuais } & $\begin{array}{l}\text { Qual é o grau de autonomia do responsável pelo programa? (Ellis, 1991; } \\
\text { Reppucci \& Saunders, 1974) }\end{array}$ \\
\hline & $\begin{array}{l}\text { Existem contingências favoráveis para pagamento e treinamento de equi- } \\
\text { pe? (Cohen \& Fillipczac, 1971; Reppucci \& Saunders, 1974) }\end{array}$ \\
\hline & $\begin{array}{l}\text { Quais são as condições financeiras para criação e implementação do pro- } \\
\text { grama? (Ellis, 1991; Emery \& Marholin, 1977; Latessa, 2004; Reppucci \& } \\
\text { Saunders, 1974) }\end{array}$ \\
\hline
\end{tabular}




\section{População-Alvo}

A análise de uma política de reintegração social deveria partir da identificação da população à qual ela se destina. Andrews, Bonta, Hoge, Zinger, et al. (1990) afirmam que as características de um programa deveriam ser definidas a partir da identificação dos participantes, já que alguns serviços são mais adequados a um tipo de população do que outros.

Embora esta afirmação possa parecer um truísmo, a análise de políticas voltadas para o presidiário sugere que, na prática, isso nem sempre acontece (Guimarães, 2008). Da mesma forma, a questão vai além da simples afirmação da necessidade de se levar em conta as características da população-alvo. Há evidências de que especificidade na condição do presidiário altera o sucesso de um programa. Como indicado na pesquisa de Andrews, Bonta, Hoge, Zinger, et al. (1990), programas de intervenção intensivos obtêm melhores resultados entre participantes considerados graves.?

Uma primeira leitura do MPRS (SAP, 2005) indica a dificuldade de se classificar o públicoalvo, uma vez que as denominações empregadas para essa classificação são ambíguas. Por exemplo: a indicação "população carcerária" nada acrescenta uma vez que, em se tratando de uma política voltada a presidiários, não se esperaria outra população. Em síntese, o rol das populações atendidas pelos projetos informa pouco sobre condições específicas delas, provavelmente pelo emprego de diferentes critérios de classificação (ora o regime, ora a condição da pena, ora o histórico de prisão, enfim, reincidente ou primário). Embora muitos destes termos sejam precisos (sabe-se, por exemplo o que é um réu primário ou um reincidente), eles são insuficientemente esclarecedores das condições de vida e de interesses dos indivíduos para os quais os programas de reintegração social são elaborados.

7 Não há referência direta do que os autores consideraram como casos graves, mas por inferência parece guiar a definição do tipo de delito, a conduta no ambiente prisional e o número de reincidências.
A ausência de descrição acerca da população-alvo pode, em primeiro lugar, dificultar ou comprometer a formulação dos objetivos e procedimentos do projeto. Além disso, a avaliação de eficácia, assim como do planejamento para futuras replicações, fica comprometida.

\section{Objetivos dos Projetos}

A formulação clara dos objetivos da intervenção é um dos pontos importantes citados por diversos autores para o exame e planejamento de um projeto de intervenção (Andrews, Bonta, \& Hoge, 1990; Andrews, Bonta, Hoge, Zinger, et al., 1990; Cohen \& Filipczak, 1971; Emery \& Marholin, 1977; Holland, 1978; Reppucci \& Saunders, 1974; Susman \& Nietzel, 1990). Mais do que isso, recomenda-se a clara explicitação de comportamentos-alvo e, dependendo do objetivo, a individualização da intervenção. Os objetivos de um projeto devem ser precisamente formulados, pois esse é um elemento fundamental para que o responsável pelo projeto possa avaliar a sua relevância. Para Popham e Baker (1978a, 1978b), a melhor maneira de se fazer isso é estabelecendo os objetivos em termos do comportamento esperado do sujeito. Um bom objetivo deveria especificar a instalação do comportamento terminal a ser emitido na situação natural e/ou prever os comportamentos intermediários e a sua mudança gradual para o comportamento terminal.

Andrews, Bonta, Hoge, Zinger, et al. (1990) sugerem que atividades que diminuam a necessidade criminogênica ${ }^{8}$ são importantes para um programa mais amplo de reintegração social uma vez que sua redução acompanha a redução da reincidência. Desta forma, para os autores, os serviços mais eficientes são aqueles que têm como objetivo intermediário reduzir as necessidades criminogênicas. Alvos intermediários promissores incluiriam: (a) mudar comportamentos antissociais, sentimentos em relação a

8 Necessidade criminogênica foi o termo dado pelos autores a fatores de risco dinâmicos que, quando alterados, são associados a uma variação subsequente nas chances de se comportar criminalmente. 
pessoas do mesmo grupo e relacionamentos com elas; (b) promover melhora na relação afetiva familiar combinada com aumento no monitoramento e supervisão por parte da família; (c) promover a identificação com modelos anti-criminais; (d) aumentar habilidades de autocontrole e autogerenciamento; (e) substituir habilidades de mentir, roubar e agredir por outras habilidades pró-sociais; (f) reduzir a dependência química; (g) e, em geral, mudar a densidade de reforço e os custos de resposta para as atividades criminais e não criminais em situações familiares, acadêmicas, vocacionais e em outros settings comportamentais.

Em teoria, modificar contingências comportamentais dentro de casa, escola e trabalho como forma de aumentar a densidade do reforço para atividades não criminais pode reduzir a motivação para o crime e aumentar o custo de resposta para atividades criminais, uma vez que o sujeito teria mais a perder se envolvendo neste tipo de atividade. Dessa forma, pode-se dizer que objetivos importantes a um projeto seriam aqueles que levassem em consideração os comportamentos do indivíduo que pudessem ampliar a probabilidade de prepará-lo para enfrentar contingências em seu ambiente natural.

Nos objetivos dos projetos do MPRS (SAP, 2005), raramente era apresentado o comportamento-alvo da intervenção. Quando isso ocorria, muitas vezes era expresso em termos tão amplos que permanecia a dificuldade de determiná-lo. Exemplos disso podem ser observados nos seguintes trechos dos projetos:

Facilitar o período de transição entre o Regime Fechado e o Regime Semiaberto com a intenção de resgatar a dignidade, cidadania perdida e autoestima do preso, possibilitando seu crescimento pessoal e facilitando sua reintegração social com uma melhor qualidade de vida. . . . Despertar, na pessoa do reeducando, a importância da sua liberdade e, consequentemente, motivá-lo para o processo de mudanças. Conscientizá-lo da necessidade de uma ressocialização para a sua inserção na sociedade, oferecendo oportunidade para o mesmo desenvolver seu censo crítico, refletindo sobre as neces- sidades a serem supridas, levando-o assim ao conhecimento pessoal, apesar da influência do meio. Direcionar a reintegração e a ressocialização em busca de novos rumos. (Guimarães, 2008, p. 61)

Estes trechos são exemplos de objetivos que, por serem amplos e pouco específicos no que se pretende atingir em que se espera resultado, dificultam tanto a elaboração de atividades específicas quanto de indicadores de atingimento dos mesmos.

Outro problema encontrado nos objetivos de projetos do MPRS (SAP, 2005) foi o fato de que, no lugar de descrever o comportamento-alvo da intervenção que se esperava do participante, na maior parte das vezes, o que se viu foi uma descrição de algo que se esperava do técnico e não do presidiário. Desta forma, 37 projetos (58\%) não especificaram o comportamento que se esperava do preso. Além disso, nos 24 projetos em que era apontado o que se esperava que o indivíduo fizesse, os comportamentos eram amplos e vagos, como é o caso de "refletir" e "discutir".

Também é marcante o fato de que em mais da metade dos 64 projetos (37) era especificado o comportamento do técnico como alguém dando subsídios para que o participante do projeto pudesse realizar algo, embora não fosse especificado o que o técnico deveria fazer para atingir esse objetivo (SAP, 2005).

Formular objetivos amplos que permitam uma variedade de interpretações não é de grande auxílio para o planejamento de programas, pois impede o técnico de ter clareza sobre o caminho que está percorrendo e, assim, tomar decisões sobre a melhor forma de avaliar a consecução dos objetivos. Também é importante ressaltar que objetivos claros permitem que se comunique ao participante e ao técnico o que se espera deles, naquela ocasião, o que também aumenta as chances de eficácia de um projeto (Popham \& Baker, 1978a, 1978b).

\section{Procedimentos Empregados}

É desejável que no planejamento de qualquer projeto de intervenção estejam descritas as atividades que o técnico e o participante devem realizar, a fim de atingir os objetivos formula- 
dos para ele. Deve-se reconhecer que, em uma situação na qual os projetos são formulados por profissionais, trabalhando provavelmente segundo diferentes orientações teóricas, suas formulações devam estar orientadas pelas mesmas. Deste ponto de vista, um importante elemento de consistência interna do projeto exigiria que essa conexão fosse levada em consideração.

Uma vez determinado o objetivo de um programa de intervenção, dois tipos de procedimentos são considerados mais adequados para que objetivos sejam alcançados: procedimentos equivalentes e procedimentos análogos (Popham \& Baker, 1978b). Os procedimentos equivalentes fornecem ao participante oportunidades de praticar o comportamento indicado pelo objetivo, ou seja, que ele possa se engajar naquele comportamento ao longo do programa. Para tanto, é indispensável ter um objetivo explícito, formulado em termos comportamentais. Os procedimentos análogos são aqueles que fornecem ao participante a possibilidade de desempenhar uma ação (de se comportar) de forma semelhante, mas não idêntica ao comportamento terminal explicitado pelo objetivo.

Em contraponto a esses dois tipos de procedimentos, estão as práticas consideradas irrelevantes. São assim chamadas por não fornecerem aos participantes possibilidade de treinar os objetivos estabelecidos, tornando, dessa forma, baixas ou nulas as chances do comportamento ser estabelecido ao final da intervenção (Popham $\&$ Baker, 1978b). Fica claro que na medida em que atividades se afastam da equivalência, as chances de se tornarem irrelevantes aumenta.

No MPRS (SAP, 2005), as atividades mais citadas nos projetos e as que mais aparecem nos procedimentos são dinâmicas de grupo, leituras de texto e discussões de grupo. Esses três tipos totalizaram $79,4 \%$ das atividades e se os "objetivos secundários" não forem considerados, essa porcentagem chega a $96,9 \%$.

Chama a atenção o elevado número de atividades que envolvem leitura de textos, o que sinaliza pelo menos mais dois problemas. O primeiro deles diz respeito ao fato de que se a atividade é constituída apenas por leituras então não será possível ao técnico identificar comportamentos do presidiário e agir sobre eles.
O outro problema reside no fato de que mesmo nas atividades em que a leitura é seguida de discussão, o técnico conta com poucos elementos para modelar um repertório comportamental. Por exemplo, é possível que o objetivo da atividade "leitura e leitura e/ou discussão de texto" seja o de aumentar a probabilidade de que as situações propostas pelo texto venham a controlar o comportamento do indivíduo quando ocorrerem em situações mais naturais. Estar-seia diante de uma situação em que se procuraria colocar o comportamento sob controle de regras. No entanto, para isso, é primeiro necessário que o comportamento de seguir regras seja modelado, pois não é a simples descrição de contingências que produzirá alterações no repertório do indivíduo. A descrição só produzirá alterações se tiver adquirido função de estímulo discriminativo ou de estímulo condicional por meio de reforçamento diferencial (Skinner, 1974).

Pela leitura dos objetivos e das atividades, não foi possível identificar em que medida o indivíduo era incitado a tomar papel ativo no programa e nem quantas oportunidades eram concedidas aos participantes para emissão de comportamentos-alvo, também não identificados, e sua consequenciação. Para que possuam maiores chances de eficácia, é importante que procedimentos estejam de acordo com os objetivos do projeto e que levem as características citadas em consideração.

\section{Avaliação}

A avaliação é um ponto essencial no planejamento de um programa de intervenção (Cohen \& Filipczak, 1971; Davidson \& Seidman, 1974; Emery \& Marholin, 1977; Susman \& Nietzel, 1990). Para a análise do comportamento, tanto o momento em que a avaliação é feita quanto o tipo de avaliação são importantes.

Para Popham e Baker (1978b), o primeiro passo para uma intervenção é determinar seus objetivos e o segundo é fazer uma avaliação prévia dos participantes. Isso porque esta avaliação pode revelar se os participantes já contam, em seu repertório, com os comportamentos que se pretende ensinar ou até mesmo indicar a ausência de habilidades preliminares necessárias. 
Desta forma, é possível, se necessário, adaptar as metas selecionadas, eliminando algumas e, quiçá, acrescentando outras. Além disso, a avaliação prévia é fundamental, pois será usada como peça de confronto das avaliações pós-término para se determinar a eficácia do programa.

A análise dos projetos apresentados no MPRS revelou que poucas medidas observáveis são planejadas pelos projetos. No momento anterior à intervenção, nenhuma medida é solicitada e apenas em um projeto (cf. Guimarães, 2008, p. 81) existe uma medida observável planejada para o decorrer da intervenção. Ao término das intervenções, 14 projetos $(21,9 \%)$ solicitam uma medida observável, sendo "diminuição no índice de reincidência" a mais frequente. Por um lado, a medida está de acordo com a maior parte dos objetivos dos projetos, que são amplos e se propõem a reduzir a reincidência. Por outro lado, a medida não seria suficiente para avaliar o programa, uma vez que muitas outras variáveis estão envolvidas.

Também chama a atenção que a medida mais utilizada pelos projetos seja "impressões (expectativas) do preso", tendo sido escolhida por $5(7,8 \%)$ projetos antes da intervenção, $18(28,1 \%)$ durante e $51(79,7 \%)$ ao término. É válido colher a opinião do participante sobre a intervenção, uma vez que ela pode revelar aspectos relevantes como motivação dos mesmos. No entanto, a medida mereceria cuidados, uma vez que os relatos podem ser distorcidos por influência de variáveis externas e, portanto, a precisão do autorrelato pode estar relacionada a outras variáveis que não o próprio relato (Critchfield \& Perone, 1993). Critchfield (1996) afirma que, de forma geral, indivíduos tendem a relatar mais ações socialmente desejadas e menos ações socialmente indesejadas.

Ao mesmo tempo, projetos que se propõem a iniciar uma sistematização da reintegração social deveriam ter uma maior preocupação com a avaliação. Nesse sentido, seriam necessários outros instrumentos de medida que pudessem revelar se as metas da intervenção foram ou não alcançadas.

\section{Condições Contextuais}

Saber sobre os recursos e condições necessárias e disponíveis para a implementação do projeto pode dizer muito sobre os mesmos, já que sem recursos físicos e financeiros o planejamento de uma intervenção de reintegração social pode ficar comprometido. Da mesma forma, eles podem constituir indicador da importância do projeto para o Governo e/ou entidades parceiras.

Não se pode esquecer que os projetos são, em sua maioria, destinados a indivíduos cumprindo pena e que, nessa situação, o projeto acontece dentro dos muros da instituição. Portanto, deveria haver uma preocupação constante em criar situações que favoreçam a generalização das situações aprendidas em um local para o ambiente natural.

Reppucci e Saunders (1974) relatam que a verba para a implementação do projeto é fundamental não apenas para cobrir os gastos com material a ser utilizado e com pagamento da equipe, mas também para cobrir os gastos com a avaliação do programa. Este é um item dispendioso em uma intervenção, mas, sem boas avaliações, pouco ou nada se pode saber da eficácia do programa (Emery \& Marholin, 1977).

Os mesmos autores também relatam que, quando a equipe é disponibilizada pela própria instituição, a contingência maior de reforçamento dos mesmos é o pagamento mensal. Caso a atividade exija esforço-extra dos trabalhadores, é desejável que sejam oferecidos a eles outros reforçadores, principalmente nos casos em que o salário mensal não esteja associado a este trabalho-extra.

Autores como Cohen e Filipczak (1971) e Reppucci e Saunders (1974) assinalam a importância de se dedicar parte do planejamento ao treinamento da equipe que participará diretamente do programa, o que torna relevante avaliar se isto está sendo feito e em que condições.

Dos 64 projetos analisados, a maior parte do material solicitado é constituído de itens de papelaria, como caneta, papel e cartolina e de espaço físico. Além destes, equipamentos da própria penitenciária são solicitados em alguns momentos, como o uso de videocassete e televisão. 
Analisando os dois itens anteriores, que poderiam envolver um custo adicional, fica claro que o material, a estrutura e a equipe solicitados são recursos já presentes na instituição, aparentemente não oferecendo novos custos para a mesma.

Passa-se, então, a analisar o terceiro ponto que envolve direcionamento de recursos financeiros: o pagamento e treinamento da equipe.

No que diz respeito ao treinamento da equipe, não foi possível encontrar elementos que indicassem uma ação sistemática de treinamento dos técnicos. Em relação à capacitação dos autores, é informado apenas que, no MPRS (SAP, 2005), os 64 projetos elaborados são "resultado de um longo trabalho de encontros, palestras, análises, discussões e supervisões iniciados em setembro de 2002 e concluído em fevereiro de 2005 " (p. 4). É de se supor que esses encontros tenham constituído oportunidade de formação dos criadores dos projetos. Tudo indica que as ações em relação aos projetos se resumiram a encontros preparatórios "quando foram discutidos o programa e o roteiro dos projetos" (p. 4) e três "ciclos de encontros regionais" onde eram feitas "discussões e supervisão dos projetos de reintegração social elaborados pelos profissionais"(p. 4). Mais uma vez, segundo o MPRS, ao final dos encontros foi oferecida aos autores uma "devolutiva acerca dos critérios ... (para publicação no manual)" (p. 6).

Em síntese, no que diz respeito ao treinamento de profissionais, os poucos elementos encontrados permitem dizer que os autores contaram com encontros, supervisões etc. e discussões e supervisão dos projetos por eles elaborados. No entanto, não há nada que permita detalhar em que nível isso ocorreu e com que eficiência.

Outra forma de se analisarem os recursos humanos dos projetos é olhar para o número de técnicos e funcionários ${ }^{10}$ envolvidos, bem como

São apresentados 4 diferentes dias, mas não se pode depreender do texto se o encontro se constituía em um período de quatro dias ou apenas 1 dia.

10 A palavra Funcionário tem se referido, nesse trabalho, a pessoas que trabalham dentro da penitenciária, como agentes penitenciários, e que suas profissões. Tais informações são potencialmente relevantes, já que podem constituir uma medida indireta da importância atribuída ao projeto. Por exemplo, a existência de projetos para os quais os funcionários já contratados da penitenciária tivessem sido apenas realocados para realizar uma função para a qual não foram a princípio treinados, sugeriria pequena importância dada, em última instância, pelo Estado ao projeto. É preciso reconhecer que, na melhor das hipóteses, tal programa seria limitado no seu âmbito de atuação e/ou nos seus objetivos.

A indicação desses elementos não pressupõe que bons projetos signifiquem custos elevados. Por exemplo, o uso de cartões telefônicos como reforçador usado em um dos projetos é pouco custoso. No entanto, quase nenhuma consequência como esta é empregada nos projetos do MPRS. Possíveis reduções de pena ou ganho de benefícios não representariam dispêndio financeiro para a instituição.

Ainda em relação aos custos, as propostas relativas à avaliação adotaram soluções bastante viáveis. Por exemplo, em um projeto que buscou aumentar comportamento religioso, os técnicos perguntavam ao pastor da igreja a respeito da frequência do sujeito a missas. Em outro projeto, que procurou intensificar os laços afetivos, os autores resolveram contar o número de cartas que cada um dos participantes recebia.

Se, por um lado, a relação alto custo vs. eficiência não é necessariamente verdadeira, geralmente o processo de construir um projeto de reintegração social e acompanhar o seu impacto pode ser lento e oneroso (Reppucci \& Saunders, 1974), já que é desejável envolver treinamento extensivo de técnicos e um processo de avaliação de longo prazo.

Condições contextuais que sejam favoráveis para a elaboração de projetos e de políticas de reintegração social, demandariam não apenas

poderiam e deveriam ser também alvo de projetos de reintegração social. Por outro lado, técnicos, tem se referido especialmente as pessoas que são responsáveis por alguma determinada área de conhecimento, e que em sua maioria fazem parte na construção dos projetos. 
disponibilização de verbas como também um arranjo especial de contingências sociais e legais, que favorecessem a reintegração.

\section{Considerações Finais}

Trabalhar com a reintegração social é um desafio para todas as áreas do conhecimento e em especial para a psicologia. Observa-se uma realidade austera, como descrita no relatório da Organização dos Estados Americanos (OEA, 2003), em que as condições de vida para os presos e as de trabalho para os técnicos e funcionários são muito precárias.

Persistir no caminho que vem sendo trilhado nas últimas décadas, aplicando penas privativas de liberdade cada vez mais longas e aumentando a superlotação de presídios é, no mínimo, improdutivo como política e desumano como tratamento (Carvalho, 2002; Rolim, 2003).

A análise do comportamento entende que é difícil planejar uma sociedade sem prisões (Sidman, 1989), mas também entende que uma situação ideal de reintegração social envolveria entrar cada vez mais em contato com as contingências naturais, para que um repertório alternativo fosse estabelecido (Holland, 1978). As habilidades sociais necessárias para a convivência não podem ser facilmente aprendidas em um ambiente onde a possibilidade de praticá-las esteja distanciada ou tenha sido removida dos indivíduos.

Os princípios da análise do comportamento fornecem uma base comum para a análise e compreensão de fenômenos tão amplos e tão diversos como é o caso da reintegração social. Este trabalho partiu de uma literatura analítico-comportamental e apresentou propostas para localizar elementos relevantes que deveriam estar presentes em roteiros para a elaboração e nos projetos de reintegração social.

\section{Referências}

Andrews, D. A., Bonta, J., \& Hoge, R. D. (1990). Classification for effective rehabilitation: Rediscovering psychology. Criminal Justice and Behavior, 17(1), 19-52.
Andrews, D. A., Bonta, J., Hoge, R. D., Zinger, I., Gendreau, P., \& Cullen, F. T. (1990). Does correctional treatment work? A clinically relevant and psychologically informed meta-analysis. Criminology, 28(3), 369-404.

Carvalho, L. F., Filho. (2002). Folha explica: A Prisão. São Paulo: Publifolha.

Cohen, H., \& Filipczak, J. (1971). A new learning environment. New York: Jossey-Bass.

Critchfield, T. S. (1996). Differential latency and selective nondisclosure in verbal self- reports. The Analysis of Verbal Behavior, 13(1), 49-63.

Critchfield, T. S., \& Perone, M. (1993). Verbal selfreports about matching to sample: Effects of the number of elements in a compound sample stimulus. Journal of the Experimental Analysis of Behavior, 59(1), 193-214.

Cullen, F., Lutze, F., Link, B., \& Wolfe, N. (1989). The Correctional orientation of Prison Guards: Do Officers Support Rehabilitation? Federal Probation Quarterly, 53(1), 33-42.

Davidson, W. S., \& Seidman, E. (1974). Studies of behavior modification and juvenile delinquency: A review, methodological, critique, and social perspective. Psychological Bulletin, 81(12), 998-1011.

Ellis, J. (1991). Contingencies and metacontingencies in correctional settings. In P. A. Lamal (Ed.), Behavioral Analysis of societies and cultural practices (pp. 201-217). New York: Hemisphere.

Emery, R. E., \& Marholin, D. (1977). An applied behavior analysis of delinquency: The irrelevancy of relevant behavior. American Psychologist, $32(10), 860-873$.

Guimarães, T. A. M. C. (2008). Análise de projetos para reintegração social de presidiários no Estado de São Paulo, com base em critérios extraidos de uma literatura analítico comportamental (Dissertação de mestrado em Psicologia Experimental: Análise do Comportamento, Pontifícia Universidade Católica de São Paulo, SP, Brasil).

Holland, J. (1978). Behaviorismo: Parte do problema ou parte da solução. Journal of Applied Behavior Analysis, 11(1), 63-174.

Latessa, E. (2004). The challenge of change: Correctional programs and evidence based practices. Vollmer Award Adress, 3(4), 547-560. 
Ministério da Justiça. (1984). Lei de Execuções Penais. Recuperado em setembro de 2012 de http:// www.planalto.gov.br/ccivil_03/leis/L7210.htm

Ministério da Justiça. (2012, jun.). Estatística população carcerária. Recuperado em agosto de 2012 de http://www.infopen.gov.br/

Organização dos Estados Americanos. (2003). Country Report on Brazil. Retrieved June, 2007, from http://www.cidh.org/Publicacoes.htm

Popham, J., \& Baker, E. (1978). Como estabelecer metas de ensino (Z. G. Lewin, Trad.). Porto Alegre, RS: Globo.

Popham, J., \& Baker, E. (1978). Como planejar a sequência de ensino (C. Ramos \& L. C. dos Santos, Trads.). Porto Alegre, RS: Globo.

Reppucci, N. D., \& Saunders, J. T. (1974). Social psychology of behavior modification: Problems of implementation in natural settings. American Psychologist, 29, 649-660.

Rolim, M. (2003, October 27). Prison and ideology: Limits and perspectives to prison reform in Brazil. Paper presented at the "Crime and punishment under the Lula administration: Challenges for a government of the Left", Centre for Brazilians Studies, University of Oxford, UK.
Secretaria da Administração Penitenciária do Estado de São Paulo. (2005, fev.). Manual de Projetos de Reintegração Social. São Paulo, SP: Autor. Recuperado em julho, 2007 de http://www.sap. sp.gov.br

Sidman, M. (1989). Coerção e suas implicações. Campinas, SP: Livro Pleno.

Skinner, B. F. (1974). Sobre o Behaviorismo (12. ed.). São Paulo, SP: Cultrix.

Skinner, B. F. (1981). Ciência e Comportamento Humano. São Paulo, SP: Martins Fontes. (Trabalho original publicado em 1953)

Susman, D. T., \& Nietzel, M. T. (1990). Crime and Aggression/ Child and Spouse Abuse. In A. S. Bellack, M. Hersen, \& A. E. Kazdin, International Handbook of Behavior Modification and Therapy (pp. 523-545). New York: Plenun Press.

Recebido: 05/11/2012

$1^{a}$ revisão: $27 / 02 / 2013$

Aceite final: 16/04/2013 